\title{
Molecular medicine: promises, promises?
}

\author{
Michael Steel
}

J R Soc Med 2005;98:197-199

Within the past few months, Francis Crick and Maurice Wilkins, two of the three men who won a Nobel Prize for describing the structure of DNA, have died. Their obituaries revisited the famous 1953 Nature papers, ${ }^{1,2}$ recalling with relish the classic English understatement 'It has not escaped our notice that the specific pairing we have postulated immediately suggests a possible copying mechanism for the genetic material'. In reality, Crick, at least, was less subdued, bursting in to the Eagle tavern in Cambridge with James Watson and declaiming to the doubtless bemused clientele 'we have found the secret of life'. 3,4

It was not immediately apparent how knowledge of that secret might affect the practice of medicine. Many years were spent developing the pure science of molecular biology, understanding the principles not only of DNA replication but also of transcription, translation and regulation of gene expression. Development of techniques to analyse and manipulate genetic material took even longer and will doubtless continue indefinitely. However, by the early $1970 \mathrm{~s}$ the prospect of in vitro production of therapeutic proteins by recombinant DNA technology was generating both academic and commercial interest. ${ }^{5}$ The number of identical human genes began to rise exponentially from about the same period, and in 1989 the Human Genome Project was inaugurated, reaching its conclusion some fifteen years later. ${ }^{6}$

Expectations of molecular medicine, in diagnosis and therapy, were aired only occasionally in the 1970s, but 1982 saw the publication of the first edition of David Weatherall's classic book The New Genetics and Clinical Practice, which offered in fewer than 150 pages a balanced, informed and percipient view of what was then - and what might become-possible. ${ }^{7}$ Weatherall's caution and his recognition of the realistic (long) timescale for the practical application of molecular technology in medicine were not shared by all commentators. Many enthusiasts encouraged expectation of a complete understanding of the basis of disease, rapid and precise diagnosis, repair or replacement

Michael Steel, DSc FMedSci, is newly retired from the chair of Medical Science, Bute Medical School, St Andrews University. Formerly he was Assistant Director of the MRC Human Genetics Unit, Edinburgh.

Bute Medical Building, St Andrews KY16 9TS, Scotland, UK

E-mail: cms4@st-andrews.ac.uk of defective genes where that was appropriate, or recourse to rationally designed, powerful and specific drugs where it was not. Yet in 2005, for the most part we are still waiting, and hope deferred has led to widespread disillusionment. At gatherings of clinicians, proponents of molecular medicine have almost replaced Health Service managers as the preferred butt of cruel (and, for some reason, usually salacious) humour. Elsewhere, the entire edifice of molecular biology has been dismissed as worthless in the field of medicine. ${ }^{8}$

Is this backlash simply a symptom of frustration because the underlying complexities of the human genome and its operation were insufficiently appreciated ${ }^{9}$ and, if so, will the new genetics, in the fullness of time, come into its own? With at least two decades of experience behind us, how should we evaluate the place of molecular biology in medicine?

\section{Gene therapy}

If a disorder can be attributed to an identifiable gene defect - that is, to an aberration in DNA sequence - then correction is the obvious solution. Technically, most elements of the process are well within our compass but obstacles to gene delivery have proved hard to surmount. These, in turn, have generated serious ethical dilemmas. ${ }^{10}$ Thus, only one genetic disorder may have been 'cured', to date, by gene replacement ${ }^{11}$ and that condition (adenosine deaminase deficiency) is so rare that, even if success could be guaranteed for all patients, the cost of providing therapy outside the research environment would be prohibitive. More common single gene disorders such as cystic fibrosis (CF) or haemophilia A are in many ways attractive candidates for this approach. The level of gene product (CFTR or clotting factor VIII) does not seem to be critical for therapeutic benefit. The principal target cells (respiratory mucosa and liver parenchyma, respectively) are accessible and animal models have provided some encouraging results. However, in the case of $\mathrm{CF}$, adults with already compromised lung function do not tolerate the inflammation that accompanies delivery of the gene construct via an adenovirus vector and artificial liposomes have not yet proved effective alternatives. For both conditions the most suitable recipients of gene therapy would be young children, yet there is a natural reluctance 
to undertake protocol developments in children. Furthermore, an effective treatment (use of recombinant factor VIII) already exists for haemophilia A, while the approaches currently under development for CF would address only the pulmonary defects, not the pancreatic or other manifestations. ${ }^{12}$

The potential hazards of gene therapy ${ }^{10}$ have been recognized from the very start and strict regulatory regimens have been established in all countries where it is undertaken. Deaths directly attributable to the procedures have been recorded; one, at least, was caused by deviation from the prescribed protocol ${ }^{13}$ but two others, deemed unavoidable, were due to random insertion of a vector sequence at a site that induced leukaemic cell proliferation. ${ }^{14}$ These experiences have tempered enthusiasm for the general approach and partly account for the continuing preponderance of malignancies among the conditions for which gene therapy proposals have been submitted. ${ }^{15}$

Efficiency of transgene delivery is even more of a limitation in the cancer setting, but several variations on the broad theme of gene therapy have shown promise. Introduction of the herpesvirus thymidine kinase, for example, renders cells susceptible to ganciclovir (virusdirected enzyme pro-drug therapy) while a modified adenovirus capable of replicating in (and hence lysing) p53-deficient tumour cells appears to work, up to a point. ${ }^{15}$ No cures, then, but enough encouragement for work to continue.

If the term 'gene therapy' is widened to include manipulation of the genome without the introduction of extraneous genes, then the remarkable potential of selective gene silencing by 'small interfering RNA' molecules (siRNAs) ${ }^{16}$ deserves a mention, if only to counter the general gloom. Furthermore, if we can crack one of the greatest remaining problems in molecular biology, how to reactivate silenced genes such as eutrophin and haemoglobin gamma chain, great things may be achieved - in these examples, for Duchenne muscular dystrophy and beta thalassaemia, ${ }^{17}$ but the ultimate range of applications would be very wide indeed.

\section{Diagnosis}

There are much more impressive success stories in the field of diagnosis. Molecular characterization of viruses and bacteria is relatively easy and, particularly since the almost universal application of the polymerase chain reaction to amplify minute quantities of nucleic acids, ${ }^{18}$ molecular techniques have proved invaluable for the early and precise identification of pathogens. One of the most important benefits has been a much clearer appreciation of sources and routes of spread of a wide range of infectious diseases, from predicted on the basis of gene analysis and we can expect this approach to replace conventional culture techniques in routine microbiological practice. ${ }^{21}$

For non-infectious diseases, the surge in recognition of human genes has improved the precision with which single gene disorders (and some contiguous gene syndromes) can be identified. ${ }^{22}$ The major clinical impact has been in the area of prenatal diagnosis, particularly for recessive conditions (which are in the majority). In the absence of effective therapies, voluntary childlessness, selective termination of pregnancy, or preimplantation embryo screening, with all their attendant ethical dilemmas, are currently the only options. However, in the case of Tay-Sachs disease or cystic fibrosis, for example, which have a sizeable incidence in certain populations, carrier screening is already reducing the numbers of affected children. ${ }^{23}$ Genetic diseases with later onset present particular problems. The uptake of definitive predictive testing for Huntington's disease is very low, though this is likely to change dramatically if and when ways are discovered to forestall symptoms. ${ }^{24}$ Testing for mutations that predispose to adenomatous polyposis coli or to familial breast/ovarian cancer is more widely acceptable because those who are found not to be at increased risk can be spared intensive (and uncomfortable) screening while mutation carriers have the option of prophylactic surgery ${ }^{25-27}$ - not perhaps an ideal measure but, for many, the lesser of two evils. The verdict here must be 'could do better'.

A less predictable outcome of advances in molecular medicine has been the growing recognition of the diversity within cancers. ${ }^{28}$ Molecular 'profiling', by the application of gene expression microarrays and related techniques, has demonstrated, with particular clarity, that cancers, even of the same organ and of similar histological types, can differ greatly in molecular profile. ${ }^{29}$ The implication is that they may differ also in aetiology, in prognosis and, importantly, in response to specific therapies, but exploitation of these findings for the benefit of patients is in its infancy.

\section{Drug design}

In principle, if we understand mechanisms of disease at the molecular level, we should be able to develop specific strategies, using small molecules (i.e. drugs) to correct or circumvent the abnormality. This is in direct contrast to traditional routes of drug discovery - folklore, serendipity, 'trial and error'. An early and dramatic illustration of the 'rational' approach was the use of high-dose retinoic acid to induce remission in acute promyelocytic leukaemia, ${ }^{30}$ following the finding that the chromosome translocation characteristic of that condition inactivates the retinoic acid alpha receptor. The worldwide threat of HIV proved a powerful stimulus to the design of drugs that could interfere 
with the limited functions of a retrovirus, leading to inhibitors of both reverse transcriptase and viral proteases. ${ }^{31}$ Monoclonal antibodies directed against HER2 (for breast cancer) ${ }^{32}$ or TNF (for rheumatoid arthritis) ${ }^{33}$ and specific protein kinase inhibitors (Iressa [gefitinib]; Gleevec [imatinib mesylate]) are other examples of a new wave of agents aimed at specific molecular targets, ${ }^{34}$ which, though not yet the ultimate 'magic bullets', hold out prospects of greatly enhanced effectiveness and reduced toxicity. ${ }^{35}$ One lesson already learned from the early experience of rational drug design is that our understanding of molecular processes is still very limited. Who would have thought that selective COX2 inhibitors would differ so much from unselective blockade of cyclo-oxygenase in subsequent risk of thromboembolic events? ${ }^{36}$ Yet surprises have educational value. From them we shall gain useful insights into the complexities of human physiology and, with patience, will learn to apply that knowledge.

Like so many of the commercial ventures it has spawned, molecular biology may be a long time in paying a dividend, but it is starting to do so ${ }^{37}$ and the big payoff, for patients and investors alike, will come from its merger with pharmacology.

\section{REFERENCES}

1 Watson JD, Crick FHC. A structure for deoxyribose nucleic acid. Nature 1953;171:737-8

2 Wilkins MH, Stokes AR, Wilson HR. Molecular structure of deoxypentose nucleic acids. Nature 1953;171:738-40

3 Watson JD. The Double Helix. New York: Norton, 1980

4 Judson HF. The Eighth Day of Creation: Makers of the Revolution in Biology. New York: Cold Spring Harbor Press, 1996

5 Anon. Steps on the road to modern day biotechnology [http:// fig.cox.miami.edu/-cmallery/150/hisbiotech/hisbiotech.htm] Accessed February 2005

6 Human Genome Project [www.ornl.gov/sci/techresources/ Human_Genome/home.shtml]. Accessed February 2005

7 Weatherall DJ. The New Genetics and Clinical Practice. London: Nuffield Hospitals Provincial Trust, 1982

8 Le Fanu J. The Rise and Fall of Modern Medicine. London: Little, Brown, 1999

9 Willard HF, Davies KE. Genetics of disease - complex genetics, complex diseases. Curr Opin Genet Dev 1998;8:271-3

10 Kimmelman J. Recent developments in gene transfer: risks and ethics. BMJ 2005;330:79-82

11 Aiuti A, Ficara F, Cattaneo F, Bordignon C, Roncarlo MG. Gene therapy for adenosine deaminase deficiency. Curr Opin Allergy Clin Immunol 2003;3:461-6

12 Pfeifer A, Verma IM. Gene therapy: promises and problems. Annu Rev Genomics Hum Genet 2001;2:177-211

13 Marshall E. Clinical trials: gene therapy death prompts review of adenovirus vector. Science 1999;286:2244-5
14 Kohn DB, Sadelan M, Glorioso JC. Occurrence of leukaemia following gene therapy of X-linked SCID 2. Nature Rev Cancer 2003;3:477-8

15 Wadhwa PD, Zielske SP, Roth JC, et al. Cancer gene therapy: scientific basis. Annu Rev Med 2002;53:437-52

16 Ryther RCC, Flynt AS, Phillips JA, Patton JG. siRNA therapeutics: big potential from small RNAs. Gene Therapy 2005;12:5-11

17 Thiel G, Lietz M, Hohl M. How mammalian transcriptional repressors work. Eur J Biochem 2004;271:2855-62

18 PCR Fact Sheet [www.genome.gov/10000207]. Accessed February 2005

19 Yirrell DL, Pickering H, Palmarini L, et al. Molecular epidemiological analysis of HIV in sexual networks in Uganda. AIDS 1998;12:285-90

20 Mazars E, Lesjean B, Bamuls AL, et al. High-resolution microsatellitebased typing as a portable approach to global analysis of Mycobacterium tuberculosis: molecular epidemiology. Proc Natl Acad Sci USA 2001;98:1901-6

21 Gillespie SH, ed. Methods in Molecular Medicine. Antibiotic Resistance, Methods and Protocols. Totowa NJ: Humana Press, 2000

22 OMIM (Online Mendelian Inheritance in Man) [www.ncbi.nlm.nih.gov/entrez/query.fcgi?db=OMIM]. Accessed February 2005

23 Khoury MJ, McCabe LL, McCabe ERB. Population screening in the age of genomic medicine. $N$ Engl J Med 2003;348:50-8

24 Scourfield J, Soldan J, Gray J, Houlihan G, Harper PS. Huntington's disease: psychiatric practice in molecular genetic prediction and diagnosis. Br J Psychiatry 2001;170:146-9

25 Lerman C, Shields AE. Genetic testing for cancer susceptibility: the promise and the pitfalls. Nat Rev Cancer 2004;4:235-41

26 Lobb E, Meiser B. Genetic counselling and prophylactic surgery in women from families with hereditary breast or ovarian cancer. Lancet 2004;363:1841-2

27 Scheuer L, Kauff N, Robson M, et al. Outcome of preventive surgery and screening for breast and ovarian cancer in BRCA mutation carriers. J Clin Oncol 2002;20:1260-8

28 Vogelstein B, Kinzler KW. Cancer genes and the pathways they control. Nat Med 2004;10:789-9

29 Hanash S. Integrated global profiling of cancer. Nat Rev Cancer 2004;4:638-43

30 Burnett AK. Presenting white cell count and kinetics of molecular remission predict prognosis in APMI treated with all-trans retinoic acid: results of randomised MRC trial. Blood 1999;93:4131-43

31 Johnston MI, Hoth DE. Present status and future prospects for HIV therapies. Science 1993;260:1286-93

32 Bell R, Verma S, Untech M, Cameron D, Smith I. Maximising clinical benefit with trastuzamab. Semin Oncol 2004;31(suppl 10):35-44

33 Maini SR. Infliximab treatment of rheumatoid arthritis. Rheum Dis Clin N Am 2004;30:329-47

34 Fischer OM, Streit S, Hart S, Ullrich A. Beyond Herceptin and Gleevec. Curr Opin Chem Biol 2003;7:490-5

35 Anon. The future of cancer treatment: up close and personal. Economist 2004;373:75-8

36 Clark DW, Layton D, Shakir SA. Do some inhibitors of COX-2 increase the risk of thromboembolic events? Linking pharmacology with pharmacoepidemiology. Drug Saf 2004;27:427-56

37 Multiple authors. The Human Genome Comes of Age. FT Biotechnology, Special Report. Financial Times, 10 November 2004 